\title{
Factors associated with the hospitalization of the elderly: a national study
}

\section{Abstract}

Objective: to analyze the factors associated with hospitalization among the Brazilian elderly based on multidimensional methodology. Method: a cross-sectional, quantitative study was performed with data from the National Health Survey (2013) populationbased study. The sample was composed of 23,815 individuals over the age of 60 years. Hospitalization was considered the outcome variable and 53 independent variables were included, relating to: sociodemographic characteristics; limitations and illness; difficulties in performing basic and instrumental activities of daily living; use of health services and medical emergencies. Results: it was found that $10 \%$ of the elderly were hospitalized in the previous year. This event was related to: a negative self-perception of health $(\mathrm{OR}=1.35)$; stopping performing any of their usual activities due to health reasons $(\mathrm{OR}=2.14)$; difficulty going to the doctor $(\mathrm{OR}=1.65)$ or walking alone (OR $=1.55)$; a recent search for a site, service or health professional for health-related care $(\mathrm{OR}=1.47)$; increased frequency of annual medical visits $(\mathrm{OR}=2.93)$ and household emergency $(\mathrm{OR}=5.40)$. Conclusion: the results reinforce the fact that multiple factors are associated with the hospitalization of the elderly. The analysis of these associations has the potential to make health professionals and administrators aware of the need to improve health care for the elderly and to assist in the organization and planning of the actions of the entire health service network.

\footnotetext{
Universidade Estadual de Ponta Grossa, Departamento de Enfermagem e Saúde Pública. Programa de Residência Multiprofissional em Saúde, Hospital Universitário Regional dos Campos Gerais. Ponta Grossa, Paraná, Brasil.

2 Universidade Estadual de Ponta Grossa, Departamento de Odontologia. Ponta Grossa, Paraná, Brasil.

3 Universidade Estadual de Ponta Grossa, Departamento de Odontologia. Programa de Pós-graduação em Ciências da Saúde. Programa de Residência Multiprofissional em Saúde, Hospital Universitário Regional dos Campos Gerais. Ponta Grossa, Paraná, Brasil.

4 Universidade Estadual de Ponta Grossa, Departamento de Enfermagem e Saúde Pública. Programa de Residência Multiprofissional em Saúde do Idoso, Hospital Universitário Regional dos Campos Gerais. Ponta Grossa, Paraná, Brasil.
}

Correspondence

Danielle Bordin

daniellebordin@hotmail.com
Danielle Bordin'

Luciane Patrícia Andreani Cabral'

Cristina Berger Fadel ${ }^{2}$

Celso Bilynkievycz dos Santos ${ }^{3}$

Clóris Regina Blanski Grden ${ }^{4}$

Keywords: Hospitalization. Health Services for the Aged. Risk Factors. Indicators of Health Services. 


\section{INTRODUCTION}

The interaction between physical and mental health, autonomy, social integration, family support and economic independence should all be considered when assessing the health of the elderly ${ }^{1}$. The challenge facing health systems is to provide comprehensive care for these users, who present unique physiological and clinical characteristics, with the potential to suffer disabilities that can impair their functional capacity ${ }^{2}$.

Although aging involves limitations inherent in its process, this age group should be allowed the possibility of managing their own life with a view to maintaining independence and autonomy, for as long as possible, contributing to their quality of life.

Concern over the conditions required to maintain the quality of life of elderly people has also increased, as the profile of diseases among the elderly usually requires more resources, with a direct impact on health services and levels of hospital utilization, especially long-term use ${ }^{3-5}$. Knowledge of the hospitalization profile of this population is an important factor in the construction of indicators for the planning and monitoring of health actions and the allocation of government resources. From this perspective, when assessing the associations and probabilities of hospitalization in the elderly, it is possible to establish a relationship with the definition of health intervention priorities, as well as with preventive measures, as the elderly are the population at greatest risk.

However, due to the costs and operational complexity of carrying out population-based epidemiological studies, the use of national level databases, aimed at generating information not yet considered in health, is important. For the present study, the chosen source of information was the most recent National Health Survey (PNS), which presents a synthesis of the perception of health status, lifestyle and chronic diseases in Brazil.

Finally, identifying the associations related to the hospitalization of the elderly allows the improvement of health planning and management tools, guaranteeing the role of the elderly in the consolidation of decisionmaking processes in Brazilian health systems. Thus, the objective of the present study was to analyze the factors associated with hospitalization among the Brazilian elderly, based on a multidimensional methodological approach.

\section{METHOD}

This cross-sectional, quantitative study is based on National Health Survey (PNS) database, a research project promoted by the Ministry of Health and conducted in 2013 by the Brazilian Institute of Geography and Statistics (IBGE) ${ }^{6}$.

The survey was carried out in the homes of the participants and employed a three-stage probabilistic sampling by cluster structure, with census sectors or group of census sectors the primary sampling units, households the secondary units and selected elderly residents the tertiary units ${ }^{6}$. The sample size was defined based on the level of precision desired for the estimates of some of the indicators of interest, resulting in information being gathered from 205,546 individuals ${ }^{6}$. Details on the sampling process and weighting are available in the PNS report ${ }^{6}$. The present study included only data from elderly individuals $(\mathrm{N}=23,815)$.

Data were collected through individual interviews and stored on handheld computers by calibrated researchers. Individuals older than 18 years participated in the study. The interview was based on three forms: household, relating to the characteristics of the household; a form relating to all the residents of the household; and an individual form, answered by a resident of the household aged 18 years or older, based on drawing by lots ${ }^{6}$. The present study considered exclusively the data of individuals over 60 years old, based on the last two forms.

The national survey was approved by the National Commission for Ethics in Research involving Human Subjects of the Ministry of Health, under approval number 328.159/2013.

The outcome variable "hospitalization" is the result of the question: "Were you hospitalized for 24 hours or more in the last 12 months?" with the answers: yes and no.

In the pre-exploration of data phase, all the variables present in the PNS corresponding to the population to be studied were listed, based on 
literature, resulting in 53 variables of interest used to compose the independent variables. These related to: sociodemographic characteristics; limitations and illness; difficulties in performing basic and instrumental activities of daily living; use of health services and medical emergencies (Table 1). All the variables were treated, with the numerical variables transformed into categorical, while others were recategorized or dichotomized as recommended in literature. In addition, due to an imbalance, the classes of the outcome variable were balanced for each independent variable using the supervised WEKA Resample Filter method $^{7}$, in order to minimize possible biases of the results.

Chart 01. Description of the independent variables used in the study. National Health Survey. Brazil, 2013.

\begin{tabular}{|c|c|}
\hline \multicolumn{2}{|l|}{ Sociodemographic characteristics } \\
\hline Gender & Marital status \\
\hline Age & Literacy \\
\hline Skin color/ethnicity & Level of education \\
\hline Live with spouse & Income \\
\hline \multicolumn{2}{|l|}{ Condition and limitations of health } \\
\hline Self-perception of general health condition & Has been bedridden \\
\hline $\begin{array}{l}\text { The presence of chronic illness, physical or mental, limits } \\
\text { usual activities in some way. }\end{array}$ & Number of days bedridden \\
\hline $\begin{array}{l}\text { Have stopped performing any of usual activities for } \\
\text { health reasons }\end{array}$ & Difficulty getting around \\
\hline $\begin{array}{l}\text { Number of days on which stopped performing usual } \\
\text { activities for health reasons }\end{array}$ & Difficulty seeing \\
\hline \multicolumn{2}{|l|}{ Difficulties in Basic Activities of Daily Living } \\
\hline $\begin{array}{l}\text { Presence of difficulty eating alone with a plate placed in } \\
\text { front of you, including holding a fork, cutting food and } \\
\text { drinking from a glass }\end{array}$ & $\begin{array}{l}\text { Presence of difficulty showering alone including entering } \\
\text { and exiting the shower or bathtub }\end{array}$ \\
\hline $\begin{array}{l}\text { Presence of difficulty in going to the bathroom alone } \\
\text { including sitting and getting up from the toilet }\end{array}$ & $\begin{array}{l}\text { Presence of difficulty walking from one room to another } \\
\text { in the house }\end{array}$ \\
\hline Presence of difficulty in dressing alone & $\begin{array}{l}\text { Presence of difficulty lying down or getting up from the } \\
\text { bed alone }\end{array}$ \\
\hline \multicolumn{2}{|l|}{$\begin{array}{l}\text { Presence of difficulty sitting on or getting up from the } \\
\text { chair alone }\end{array}$} \\
\hline \multicolumn{2}{|c|}{ Difficulties in performing Instrumental Activities of Daily Living } \\
\hline Presence of difficulty shopping alone & Presence of difficulty managing finances alone \\
\hline Presence of difficulty taking medicines alone & Presence of difficulty going to the doctor alone \\
\hline Presence of difficulty using transport alone & $\begin{array}{l}\text { Presence of difficulty managing finances alone (taking } \\
\text { care of your own money) }\end{array}$ \\
\hline \multicolumn{2}{|l|}{ Chronic diseases } \\
\hline Presence of any chronic, physical or mental illness & Work-related musculoskeletal disorder \\
\hline Diabetes & Arthritis \\
\hline Hypertension & Depression \\
\hline High Cholesterol & Chronic obstructive pulmonary disease \\
\hline Stroke or stroke & Cancer \\
\hline Chronic spinal problem & Chronic kidney problem \\
\hline
\end{tabular}


Continuation of Chart 1

\begin{tabular}{|c|c|}
\hline \multicolumn{2}{|l|}{ Use of health services } \\
\hline Place where usually seeks care when you are sick & $\begin{array}{l}\text { Usually seek care from the same place, doctor or health } \\
\text { service when required }\end{array}$ \\
\hline Time since last medical appointment & Place where last sought health care \\
\hline $\begin{array}{l}\text { Seeking a health facility, service or professional for care } \\
\text { related to your own health in the last two weeks }\end{array}$ & $\begin{array}{l}\text { Use of any integrative and complementary practice, } \\
\text { including treatment such as acupuncture, homeopathy, } \\
\text { medicinal plants and phytotherapy etc. }\end{array}$ \\
\hline Had drugs prescribed at the last visit & Home emergency \\
\hline \multicolumn{2}{|l|}{ Reason for the demand of the service } \\
\hline \multicolumn{2}{|l|}{ Habits } \\
\hline Consume alcoholic drinks & Perform physical activity \\
\hline Use tobacco & \\
\hline
\end{tabular}

After the complete treatment of the database, the dimensionality reduction test was performed using the Correlation-based Feature Selection (CFS) algorithm with the 10 -fold cross validation method ${ }^{7}$. This data mining test is recommended for use with a large set of data and variables, such as that proposed in the present study. The CFS algorithm evaluated, according to response patterns, the entire data set and the 53 variables at a single moment to search for variables that were closely related to the outcome variable, and not related to each other. It therefore considered not only the utility of the variables individually, but also the level of correlation between them, thereby eliminating any and all confounding relationships. The variables with nonexistent or weak or redundant relationships, which do not bring information to the model, are all eliminated by the algorithm, without the influence of the researcher being required. In this way, it is possible to validate the pure and strict relationships of the independent variables with the outcome variable, with much more precision than in other tests frequently used in the literature, creating a model with much greater predictive capacity?

Next, the variables related to hospitalization that made up the model were evaluated with logistic regression to measure the magnitude of the associations. The model had an explanatory capacity of $70.0 \%$. All analyzes were performed in the WEKA environment?

\section{RESULTS}

In the results of the selection analysis for the reduction of dimensionality, it was found that the variables most strongly related to the hospitalization of Brazilian elderly people were: self-perception of general health condition; stopping performing any of their usual activities for health reasons; difficulty going to the doctor and walking alone; recently seeking a health facility, service or professional for care related to one's own health; frequency of annual medical consultation and household emergency.

The descriptive analysis revealed a prevalence of $10 \%$ of hospitalization in the previous year among the elderly. Table 1 shows the descriptive analysis of the independent variables that presented a relation with the hospitalization of Brazilian elderly persons. Table 2 shows the odds ratios of the elderly who required hospital admission in the previous year, according to the independent variables.

The majority of the elderly had a negative perception of their health (Table 1), and this perception was responsible for increasing the chances of hospitalization by 1.35 times in comparison with positive perception (Table 2). Still, the majority of the elderly investigated did not find the performance of any usual activities impossible for reasons of health, or have difficulty going to the doctor or walking alone (Table 1). However, when these limitations are present, the chances of hospitalization were 2.14; 1.65 and 1.55 times greater, respectively (Table 2).

A total of $78 \%$ of the respondents had needed to be treated in a health service in the two weeks prior to the collection of PNS data (Table 1). The number of medical appointments in the previous year was up to four for the majority of the elderly persons, 
while 3\% of the participants required emergency home care (Table 1). Seeking these services increased the chances of individuals needing hospitalization (Table 2).

Table 1. Descriptive analysis of the independent variables presenting a relationship with the hospitalization of Brazilian elderly people. Brazil, 2013.

\begin{tabular}{|c|c|c|c|c|}
\hline Dependent variable & & Total $n(\%)$ & Yes $n(\%)$ & No $n(\%)$ \\
\hline Hospitalization & & $23815(100)$ & $2377(10)$ & $21438(90)$ \\
\hline \multirow[t]{2}{*}{ Self-perception of general health condition } & Positive & $10461(44)$ & $597(6)$ & $9864(94)$ \\
\hline & Negative & $13354(56)$ & $1780(13)$ & $11574(87)$ \\
\hline \multirow{2}{*}{$\begin{array}{l}\text { Failure to perform any of usual activities due } \\
\text { to health }\end{array}$} & No & $21141(89)$ & $1950(9)$ & $19488(92)$ \\
\hline & Yes & $2674(11)$ & $724(27)$ & $1653(62)$ \\
\hline \multirow[t]{2}{*}{ Difficulty going to doctor alone } & No & $18146(76)$ & $1293(7)$ & $16853(93)$ \\
\hline & Yes & $5669(24)$ & $1084(19)$ & $4585(81)$ \\
\hline \multirow[t]{2}{*}{ Difficulty walking alone } & No & $21779(91)$ & $19936(92)$ & $1843(8)$ \\
\hline & Yes & $2036(9)$ & $534(26)$ & $1502(74)$ \\
\hline \multirow{2}{*}{$\begin{array}{l}\text { Recently sought a health facility, service or } \\
\text { professional for treatment related to own health }\end{array}$} & No & $5248(22)$ & $461(9)$ & 4787 (91) \\
\hline & Yes & $18567(78)$ & $1916(10)$ & $16651(90)$ \\
\hline \multirow[t]{2}{*}{ Frequency of medical consultation in last year } & $\geq 4$ consultations & $12467(64)$ & $956(8)$ & $11511(92)$ \\
\hline & $>4$ consultations & $7036(36)$ & $1421(20)$ & $5615(80)$ \\
\hline \multirow[t]{2}{*}{ Home emergency } & No & $23140(97)$ & $2035(9)$ & 21105 (91) \\
\hline & Yes & $675(3)$ & $342(51)$ & $333(49)$ \\
\hline
\end{tabular}

Table 2. Odds ratio of hospitalization of the elderly according to independent variables. Brazil, 2013.

\begin{tabular}{ll}
\hline Variable & Odds Ratio (OR) \\
\hline Self-perception of overall health & 1.00 \\
Positive & 1.35 \\
Negative & 1.00 \\
Failure to perform any of usual activities due to health & 2.14 \\
No & \\
Yes & 1.00 \\
Difficulty going to doctor alone & 1.65 \\
No & \\
Yes & 1.00 \\
Difficulty walking alone & 1.55 \\
No & \\
Yes & 1.00 \\
Recently sought a health facility, service or professional for treatment related to own health. & 1.47 \\
No & \\
Yes & 1.00 \\
Frequency of medical consultation in last year & 2.93 \\
Up to 04 consultations per year & \\
Over 04 consultations per year & \\
Home emergency & \\
No & \\
Yes & \\
\hline
\end{tabular}




\section{DISCUSSION}

In the present study, which considers the factors associated with hospital admission among the Brazilian elderly, a prevalence of hospitalization of $10 \%$ was found. During the aging process elderly people tend to exhibit several pathologies, which contributes to a greater risk of hospitalization due to acute and chronic situations ${ }^{2,4,5}$. Hospital admission is more frequent among the elderly, regardless of the outcome, with longer periods of hospitalization and increased costs ${ }^{3,4}$, which demands the structuring of services and health programs. In this sense, research that supports the promotion of strategies to reduce such episodes, such as the present study, are important.

The results of the present study showed that elderly people with a poor perception of health had a 1.35 times greater chance of being hospitalized. This association was also found by the authors of a crosssectional study, with a population base of 686 elderly people $(p<0.006)^{8}$. It is common for the elderly to see themselves as having poor health, a fact explained by their morbidity, frailty and higher risk of mortality ${ }^{9-13}$ conditions that result in a greater demand for health services, which may explain this finding $2,3,5,11$.

One relevant fact that should be highlighted and which reinforces the importance of using selfperception of health as a health indicator is that chronic diseases alone did not exhibit a significant association with hospitalization. It can therefore be said that the general state of health goes beyond chronic conditions, and reinforces the theory that the complexity of the framework of health perceptions is much more related to subjective questions than to objective clinical demands.

Factors related to the functional ability of the elderly exhibited a strong relationship with the need for hospitalization. Authors have affirmed that functional capacity is a dynamic process and represents a central component of the health of the elderly ${ }^{12,14,15}$, as the related limitations, which either arise from or cause a decline in health ${ }^{12,14,15}$, can result in an increased need to use health services ${ }^{2,3,12,14}$.

Elderly patients with episodes of hospitalization presented a greater chance of failing to perform any of their usual activities due to health reasons and a greater difficulty going to the doctor and walking alone $(\mathrm{OR}=2.14, \mathrm{OR}=1.65$ and $\mathrm{OR}=1.55$, respectively). In a cross-sectional study involving 1,593 elderly people residing in the community, the authors found that being hospitalized at least once in the previous year resulted in around a 70\% greater disability in basic activities and a 30\% greater disability in instrumental activities ${ }^{12}$. A positive association between disability in instrumental activities and hospitalization was also found among elderly people from the state of Minas Gerais ${ }^{14}$.

The associations between the consequences of functional disability and hospitalization may be related to the fact that such limitations express a poor state of health, resulting in this positive relationship, as shown by the results of the present study regarding individuals with a negative self-perception of health. Or, they may be explained, as found in literature, by the possibility of hospitalizations resulting in the aggravation of the functional condition of the elderly person ${ }^{16-18}$.

Moreover, the context of disability can contribute to the explanation of the association between the reported need of the elderly to receive emergency care at home and hospitalization. Literature has indicated that the use of home care is associated with the difficulty of getting to a health service ${ }^{12}$ requiring, therefore, health care in the individual's own home ${ }^{14}$. In addition, the emergency service is usually triggered when the patient is in a critical health situation, exposing the individual to extreme risks, requiring specialized, high complexity care ${ }^{19}$.

It was also identified that the recent search for a health facility, service or professional for care relating to one's own health and having had more than four annual medical appointments were factors associated with hospitalization. It is understood that the regular use of the health service can be considered as an easing factor for entering the health system. In addition, the process of population aging contributes to the increased use of health services ${ }^{10}$.

Researchers from the cross-sectional study with 96 elderly people in Rio Grande do Sul reported that a higher frequency of medical consultations increases the high risk of hospital admission by $83.3 \%$ in participants with more than six annual consultations ${ }^{13}$. According to the authors, these findings do not include the possibility of preventive consultations, but are related to the treatment of established diseases ${ }^{13}$. 
Therefore, a high frequency of medical consultations and having recently sought health services indicate that these individuals suffer morbidity and/or a worse health status, requiring more health care, and that evaluation by a medical professional allows the diagnosis of health problems, increasing the likelihood of hospital admission ${ }^{13,20}$. Investment in the training in care and continuous follow-up monitoring of hospitalized elderly persons is therefore required, especially in primary care, with the aim of acting to prevent unnecessary readmissions and admissions.

The findings of the present study should be interpreted in the light of certain limitations, as in some cases the respondents were not the elderly themselves and part of the PNS data was provided by another resident of the household. However, studies have shown that the use of another respondent does not modify distribution or the associated factors ${ }^{10}$.

In addition, surveys that evaluate the use of health services are subject to obstacles regarding quality of information due to memory bias. However, considering the seriousness of the event of hospitalization in people's lives, the probability of this bias is reduced ${ }^{20}$.

The cross-sectional design was a limiting factor in the evaluation of the cause and effect relationships. However, this structure is widely used in several Brazilian and non-Brazilian surveys.

The main differentiating factor of the present is the study is its use of a significant number of independent variables, which include validated questions regarding socio-demographic characteristics, the ability to perform basic and instrumental activities of daily living, and objective and subjective factors related to health, as well as the use of health services. All were analyzed concomitantly, considering possible confounding and redundant factors that were eliminated during the attribute selection analysis, thus allowing a high degree of precision in identifying the factors most strongly associated with the hospitalization of the elderly. Another relevant point of this study is the size of the sample, which included data collection on a national level, representative of the elderly population of Brazil as a whole.

\section{CONCLUSION}

The study made it possible to identify the factors associated with the hospitalization of elderly people, raising the awareness of health professionals and managers about the need for improvements in health care for the elderly and assisting in the organization and planning of the actions of the entire health service network.

Special attention should be paid to elderly persons who do not assess their health condition positively and who present functional limitations in the performance of instrumental activities of daily living, such as failure to perform any of their usual activities, difficulty going to the doctor and walking alone. In addition, recently seeking health services or the overuse of the same, especially medical consultations and emergency home visits, should be carefully monitored.

\section{REFERENCES}

1. Paraná. Secretaria de Estado da Saúde do Paraná. Superintendência de Atenção à Saúde. Linha guia da saúde do idoso . - 1 ed. - Curitiba: SESA, 2017. 149 p.

2. Gong CH, Kendig H, He X. Factors predicting health services use among older people in China: An analysis of the China Health and Retirement Longitudinal Study 2013. BMC Health Serv Res. 2016; [citado 2018jan 22];16(1):63.Disponível em: https://www. ncbi.nlm.nih.gov/pmc/articles/PMC4758158/

3. Malta DC, Bernal RTI, Lima MG, Araújo SSC de, Silva MMA da, Freitas MIF, et al. Doenças crônicas não transmissíveis e a utilização de serviços de saúde: análise da Pesquisa Nacional de Saúde no Brasil. Rev Saude Publica. 2017; [citado 2018jan 22];51(1):1-10. Disponível em:http://www.scielo.br/pdf/rsp/v51s1/ pt_0034-8910-rsp-S1518-87872017051000090.pdf

4. Queiroz DB, Oliveira LC de, Araújo CM de, Reis LA dos. Perfil de internações de idosos em uma clínica de neurociências de um hospital público. Rev Enferm Contemp. 2016;[citado 2018jan 22];5(1):16-24. Disponível em: https://www5.bahiana.edu.br/index. php/enfermagem/article/view/441/642 
5. Nunes BP, Uhlmann M, Ii S, Wachs LS, Volz PM, Saes MO, Duro SMS, et al. Hospitalização em idosos: associação com multimorbidade, atenção básica e plano de saúde. Rev Saúde Pública. 2017; [citado 2018jan 22]; 51:(1s)1-10. Disponível em: http://www.scielo.br/pdf/rsp/v51/pt_0034-8910rsp-S1518-87872017051006646.pdf

6. Ministério da Saúde (BR).Instituição Brasileiro de Geografia E Estatística. Pesquisa Nacional de Saúde 2013 Percepção Do Estado de Saúde, Estilos de Vida e Doenças Crônicas. Brasília: Ministério da Saúde; 2014. [citado 2018 jan 22]. Disponível em: http://ftp. ibge.gov.br/PNS/2013/pns2013.pdf

7. Frank E, Hall MA, Witten IH. Data Mining: Practical Machine Learning Tools and Techniques.4. ed. (Kaufmann M, ed.). San Francisco; 2016.

8. Medeiros SM, Silva LSR, Carneiro JA, Ramos GCF, Barbosa ATF, Caldeira AP. Fatores associados à autopercepção negativa da saúde entre idosos não institucionalizados de Montes Claros, Brasil. Cien Saude Colet. 2016; [citado 2018jan 22];21(11):33773386. Disponível em: http://www.scielo.br/pdf/csc/ v21n11/1413-8123-csc-21-11-3377.pdf

9. Confortin SC, Giehl MWC, Antes DL, Schneider IJC, d'Orsi E. Autopercepção positiva de saúde em idosos: estudo populacional no Sul do Brasil. Cad Saude Publica. 2015; [citado 2018jan 22];31(5):10491060. Disponível em:http://www.scielo.br/pdf/csp/ v31n5/0102-311X-csp-31-5-1049.pdf

10. Ferreira DN, Matos DL, Loyola Filho AI de. Absence of routine medical consultation among hypertensive and/or diabetic elders: an epidemiological study based on the Brazilian National Household Survey 2008. Rev Bras Epidemiol. 2015; [citado 2018jan 22];18(3):578594. Disponível em:http://www.scielo.br/pdf/rbepid/ v18n3/1415-790X-rbepid-18-03-00578.pdf

11. Melo LA de, Sousa M de M, Medeiros AKB de, Carreiro A da FP, Lima KC de. Fatores associados à autopercepção negativa da saúde bucal em idosos institucionalizados. Cien Saude Colet. 2016; [citado 2018jan 22];21(11):3339-3346. Disponível em: http://www.scielo.br/pdf/csc/v21n11/1413-8123csc-21-11-3339.pdf

12. Nunes JD, Saes M de O, Nunes BP, Siqueira, FCV, Soares DS, Fassa MEG et al. Indicadores de incapacidade funcional e fatores associados em idosos: estudo de base populacional em Bagé, Rio Grande do Sul. Epidemiol e Serviços Saúde. 2017; [citado 2018jan 22];26(2):295-304. Disponível em:http://www.scielo. br/pdf/ress/v26n2/2237-9622-ress-26-02-00295.pdf
13. Santos FC, Rosa VF, Rosa LHT, Pribbernow SCM. Avaliação do risco de internação hospitalar de idosos da com unidade n o município de Porto Alegre. Estud interdiscipl Envelhec. 2014; [citado 2018jan 22];19(3):839-852. Disponível em:http://www.seer. ufrgs.br/index.php/RevEnvelhecer/article/view/38139

14. Fialho CB, Lima-Costa MF, Giacomin KC, Loyola Filho AI de. Capacidade funcional e uso de serviços de saúde por idosos da Região Metropolitana de Belo Horizonte, Minas Gerais, Brasil: um estudo de base populacional. Cad Saude Publica. 2014; [citado 2018jan 22];30(3):599-610.Disponível em:http://www.scielo. br/pdf/csp/v30n3/0102-311X-csp-30-3-0599.pdf

15. Cesari M, Prince M, Thiyagarajan J, et al. Frailty: An Emerging Public Health Priority. J Am Med Dir Assoc. 2016; [citado 2018jan 22];17(3):188-92. Disponível em:http://www.jamda.com/article/S15258610(15)00766-5/fulltext

16. Calero-García MJ, Ortega AR, Navarro E, Calero MD. Relationship between hospitalization and functional and cognitive impairment in hospitalized older adults patients. Aging Ment Health. 2017; [citado 2018jan 22];21(11):1164-1170.Disponível em:https:// www.tandfonline.com/doi/abs/10.1080/13607863.201 6.1220917? journalCode $=$ camh20

17. Martínez-Velilla N, Casas-Herrero A, ZambomFerraresi F, et al. Functional and cognitive impairment prevention through early physical activity for geriatric hospitalized patients: study protocol for a randomized controlled trial. BMC Geriatr. 2015; [citado 2018jan 22];15(1):112.Disponível em:https://www.ncbi.nlm.nih. gov/pmc/articles/PMC4571136/

18. Zaslavsky O, Zisberg A, Shadmi E. Impact of Functional Change Before and During Hospitalization on Functional Recovery 1 Month Following Hospitalization. Journals Gerontol Ser A Biol Sci Med Sci. 2015; [citado 2018 jan 22]; 70(3):379384.Disponível em: https://academic.oup.com/ biomedgerontology/article/70/3/381/572180

19. Caldas CP, Veras RP, Motta LB da, Guerra ACLC, Carlos MJ, Trocado CVM. Atendimento de emergência e suas interfaces: o cuidado de curta duração a idosos. J Bras Econ da Saúde, São Paulo. 2015; [citado 2018jan 22];7(1):62-69. Disponível em:http://files.bvs.br/ upload/S/2175-2095/2015/v7n1/a4757.pdf

20. Costa JSD Da, Reis MC, Silveira Filho CV, Linhares RDS, Piccinini F, Fantinel E. Prevalência de internação hospitalar e fatores associados em Pelotas, RS. Rev Saude Publica. 2010; [citado 2018jan 22];44(5):923-933. Disponível em:http://www.scielo. br/pdf/rsp/v44n5/1192.pdf 